Short communication

\title{
One-step synthesis of stereo-pure L,L lactide from L-lactic acid
}

\author{
Marzieh Ghadamyari $^{\mathrm{a}, \mathrm{b}}$, Somboon Chaemchuen ${ }^{\mathrm{a}, \mathrm{b}}$, Kui Zhou ${ }^{\mathrm{a}}$, Michiel Dusselier ${ }^{\mathrm{d}}$, Bert F. Sels ${ }^{\mathrm{d}}$, \\ Bibimaryam Mousavi ${ }^{\mathrm{a}, *}$, Francis Verpoort ${ }^{\mathrm{a}, \mathrm{b}, \mathrm{c}, *}$ \\ ${ }^{a}$ Laboratory of Organometallics, Catalysis and Ordered Materials, State Key Laboratory of Advanced Technology for Materials Synthesis and Processing, Wuhan University \\ of Technology, 430070 Wuhan, China \\ ${ }^{\mathrm{b}}$ School of Materials Science and Engineering, Wuhan University of Technology, Wuhan 430070, China \\ ${ }^{\mathrm{c}}$ National Research Tomsk Polytechnic University, Lenin Avenue 30, 634050 Tomsk, Russian Federation \\ ${ }^{\mathrm{d}}$ Center for Surface Chemistry and Catalysis, KU Leuven, Kasteelpark Arenberg 23, B-3001 Heverlee, Belgium
}

\section{A R T I C L E I N F O}

\section{Keywords:}

Lactic acid

Poly lactic acid

Lactide

MOFs

Cesium carbonate

\begin{abstract}
A B S T R A C T
Poly (lactic acid) (PLA) is extensively used as an eco-friendly compound for many applications. The synthesis of stereo-pure lactide, specifically L,L-lactide which is the most desired isomer for the synthesis of high-quality PLA is very important. In this work, various materials including MOFs and simple bases have been applied as catalysts for the Lactide synthesis. Herein we report the one-step synthesis of L,L-lactide with high selectivity and yield $(99 \%)$ in the absence of racemization by applying a cost-effective $\mathrm{Cs}_{2} \mathrm{CO}_{3}$ catalyst. The novel described procedure is even expected to be very efficient for industrial applications.
\end{abstract}

\section{Introduction}

Polymeric materials with valuable properties such as plasticity, low density, and low cost are used extensively in all aspects of our daily life. Although these materials made our life more comfortable, their generated wastes negatively affect our environment $[1,2]$. Therefore the development of bio-based plastics driven from natural or biodegradable resources attracted numerous attentions [3]. Among various bio-plastics, polylactic acid (PLA) is the major bio-plastic in the market. PLA is a biodegradable and compostable thermoplastic polyester derived from renewable sources that is widely used in various applications [4-6] PLA received much attention not only because of the environment-friendly plastic material but also due to its great versatile properties [7]. Despite all these beneficial properties, still a firm economic driver for production of a large amount of PLA is missing due to its high manufacturing and feedstock costs $[8,9]$ The industrial PLA production can be performed by three different ways: (a) direct condensation polymerization; (b) direct polycondensation in an azeotropic solution and (c) polymerization through lactide formation [10]. Unfortunately, due to the equilibrium existing between LA, water, and oligomers, the synthesis of high molecular weight PLA is problematic via polycondensation of aqueous lactic acid [11]. It was illustrated that among these three methods, ring opening polymerization of lactide is the most practicable synthetic way which could result in high molecular weight PLA with a controlled optical and crystal purity [12]. Lactide is a cyclic dimer of lactic acid (LA) which can produce three isomers: L-lactide, meso (L, D)lactide and D-lactide. Nevertheless, the existing industrial synthesis procedure of lactide is very expensive and time-consuming [11]. The method of lactide synthesis consists of two steps. Firstly, a pre-polymer is made via removal of water from the lactic acid aqueous solution and secondly, an intramolecular esterification process is performed yielding lactide [13]. Both steps are conducted at a temperature higher than $200{ }^{\circ} \mathrm{C}$ and thus demonstrating the high-energy consumption. Moreover, the final product contains a considerable amount of oligomers of lactic acid and also undesired meso-lactide [14]. Notably, the stereopure L,L-lactide is desirable to generate stereo-pure poly-L-lactic acid. The major challenges are the synthesis of stereo-pure L,L-lactide without the presence of undesired oligomers and the reduction of the reaction time by using cost-effective catalysts. Recently, many attempts were performed to improve the catalysts, and the intramolecular esterification step for the synthesis of stereo-pure L,L-lactide [14-18].

A one-step synthesis procedure of lactide includes the LA dimerization $\left(\mathrm{L}_{2} \mathrm{~A}\right)$ and direct condensation to form cyclic-dimer while controlling the growth of other oligomers [19]. Recently, Sels et al. investigated a one-step conversion of aqueous LA to lactide using Brönsted acidic zeolite catalyst and thus an impressive improvement was done compared to the current multistep industrial process [13]. Inspired by this work, we tested various catalysts including metal-organic frameworks as heterogeneous and bases as homogeneous catalysts for the synthesis of stereo-pure lactide taking the benefit of a one-

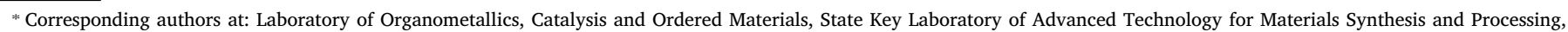
Wuhan University of Technology, 430070 Wuhan, China.

E-mail address: Francis.verpoort@ugent.be (F. Verpoort).
} 
step selective cyclic dimerization process. The results proved that MOFs (e.g. ZIF-8), as well as a simple base such as $\mathrm{Cs}_{2} \mathrm{CO}_{3}$, could be applied as an active catalyst for the one-step stereoselective synthesis of lactide.

\section{Materials and methods}

All chemicals were purchased from Aladdin Chemical Co. and Sigma-Aldrich used as received. The ZIF-8, UiO-66, MIL100 (Fe), MOF808 , Zn-DABCO were synthesized according to previous reports (SI-1) [20-22].

In a typical reaction, the requisite amount of lactic acid L-LA, the catalyst, and water were charged in a $25 \mathrm{~mL}$ round bottom flask. Subsequently, an essential amount of solvent was added which resulted in a transparent solution. On top of the round bottom flask, a custommade phase-settler, solvent reflux trap was installed and filled with the same reaction solvent $(16 \mathrm{~mL})$ before the reaction started. On top of the phase-settler, a condenser was put. This setup provided the reflux of the solvent with an easy trapping of the water. As shown in the (Fig. S3), both the solvent and water float on top and moves to the trapping part. Due to an extra amount of solvent in the trap, the solvent returns to the flask, while the water sinks to the bottom of the trap. A heating band around the system was used to keep the reflux of solvent and water constantly. After the installation of the system, the mixture was heated up for a certain time and under stirring.

\section{Result and discussion}

Various MOFs such as ZIF-8, UiO-66, MIL-100 (Fe), MOF-808, and $\mathrm{Zn}$-DABCO were synthesized according to previous reports and their material properties were characterized (Fig. S2) [20-22]. The obtained MOFs were then utilized as catalysts for the direct and one-step synthesis of lactide from lactic acid. These MOFs were chosen due to their high stability and also extensive utilization in various chemical reactions. The effect of reaction parameters on the catalysts reactivity was studied using ZIF-8 as a model study. In a typical reaction system, the desired amount of L-LA, catalyst, water, and toluene were mixed in a round bottom flask which then was connected to a liquid-liquid extraction setup. (Fig. S3) Thereafter, the mixture was applied under continuous water expunction via reflux of toluene. The initial results showed that the synthesis of lactide, free of racemization from lactic acid, could be effectively carried out at mild reaction conditions and in a short time using some of the studied MOFs. (Table 1). The yields and selectivities of the desired lactide were determined by ${ }^{1} \mathrm{H}$ NMR of which the details of the ${ }^{1} \mathrm{H}$ NMR spectra including the shifts of the lactide product are given in Fig. S4.

Table 1 displays yields, conversion of lactic acid and selectivity of lactide product under different reaction conditions.

The conversion of the substrate to lactide increased from $69 \%$ to $>99 \%$ when the temperature increased from $115^{\circ} \mathrm{C}$ to $140{ }^{\circ} \mathrm{C}$ (entries 1-3). Thereafter, the influence of the catalyst loading (40,50, and $60 \mathrm{mg}$ ) was investigated (entries 3-5). However, increasing the catalyst amount to $70 \mathrm{mg}$ was ineffective to the reaction yield (entry 6).

Subsequently, the effect of reaction time and the amount of water were investigated while the temperature and the catalyst amount were fixed at the optimum results $\left(60 \mathrm{mg}\right.$ catalyst and $\left.140^{\circ} \mathrm{C}\right)$. The reaction duration was studied at different time intervals (entries 7-8), after $2 \mathrm{~h}$ the lactide yield reached to $49 \%$. Continuing the reaction for one extra hour increased the conversion to $61 \%$ while the selectivity also increased from $72 \%$ to $80 \%$. Continuing the reaction for an additional hour resulted in $89 \%$ yield, however, further proceeding the reaction did not generate higher yields (entry 9), (Fig. S4). The ${ }^{1} \mathrm{H}$ NMR analysis illustrates the methine $\left[-\mathrm{CH}-\mathrm{CH}_{3}\right]$ quartet region of various compounds in the reaction mixtures and all signals were assigned [13].

The investigation of the amount of water on the product yield was presented in (entries 10-11). The product yield and lactic acid conversion decreased gradually by increasing the amount of water. In absence of water in a closed system (entry 12) under optimum reaction conditions $\left(140{ }^{\circ} \mathrm{C}, 4 \mathrm{~h}\right)$, a lactide yield of only $41 \%$ was reached. Moreover, in the absence of the catalyst (ZIF-8) (entry 13), the cyclodimerization of lactic acid yielded only $39 \%$.

From (Table 1) the optimum reaction conditions can be deduced as temperature $140{ }^{\circ} \mathrm{C}$, catalyst loading $60 \mathrm{mg} \mathrm{ZIF}-8,0.5 \mathrm{~mL}$ water, and toluene as solvent.

These reaction conditions were then applied for various MOFs including UiO-66, MIL-100(Fe), Zn-DABCO, MOF-808 as catalysts (Table 2). Although among various MOFs, ZIF-8 results in a higher lactide yield, still the main problem that occurs when applying other MOFs as catalyst is the generation of different side products combined with a low yield towards the desired lactide. Notably, all MOFs catalysts decomposed gradually during the reaction due to the presence of lactic acid and water in the reaction mixture combined with the high reaction temperature.

Table 1

Catalytic Performance of ZIF-8 as a catalyst for synthesis of lactide and the optimized reaction conditions.

\begin{tabular}{|c|c|c|c|c|c|c|c|}
\hline Entry & Catalyst (mg) & Time (h) & Temperature $\left({ }^{\circ} \mathrm{C}\right)$ & Amount water (mL) & Lactic acid Conversion (\%) & Yield $^{\mathrm{a}}(\%)$ & Selectivity (\%) \\
\hline 4 & 40 & 4 & 140 & 0.5 & 81 & 66 & 82 \\
\hline 5 & 50 & 4 & 140 & 0.5 & 88 & 79 & 87 \\
\hline 6 & 70 & 4 & 140 & 0.5 & 99 & 90 & 89 \\
\hline 7 & 60 & 2 & 140 & 0.5 & 69 & 49 & 72 \\
\hline 8 & 60 & 3 & 140 & 0.5 & 76 & 61 & 80 \\
\hline 9 & 60 & 5 & 140 & 0.5 & 99 & 89 & 89 \\
\hline 10 & 60 & 4 & 140 & 1.5 & 91 & 80 & 85 \\
\hline
\end{tabular}

Solvent: $5 \mathrm{~mL}$ toluene.

${ }^{\text {a }}$ Yield was determined by ${ }^{1} \mathrm{H}$ NMR using 1,1,2,2-tetrachloroethane as the internal standard. $1.77 \mathrm{mmol} \mathrm{L-lactic} \mathrm{acid} \mathrm{[13].}$ 
Table 2

Obtained lactide yield using different MOFs.

\begin{tabular}{lllll}
\hline Entry & Catalyst (mg) & $\begin{array}{l}\text { Lactic acid } \\
\text { conversion (\%) }\end{array}$ & Yield $^{\text {a }}(\%)$ & $\begin{array}{l}\text { Selectivity of lactide } \\
(\%)\end{array}$ \\
\hline 1 & UiO-66 (60) & 79 & 61 & 76 \\
2 & ZIF-8 (60) & 99 & 89 & 89 \\
3 & MOF-808 (60) & 76 & 68 & 89 \\
4 & MIL-100 (60) & 70 & 59 & 83 \\
5 & Zn-DABCO & 72 & 60 & 83 \\
& $(60)$ & & \\
6 & UiO-66 (60) & 85 & 67 & 77 \\
7 & ZIF-8 $(60)^{\mathrm{b}}$ & 94 & 92 & 99 \\
8 & MOF-808 & 76 & 74 & 95 \\
& $(60)^{\mathrm{b}}$ & & & \\
9 & MIL-100 (60) & 75 & 64 & 87 \\
10 & Zn-DABCO & 72 & 62 & 86 \\
& $(60)^{\mathrm{b}}$ & & & \\
\end{tabular}

a \%-Yield was determined by ${ }^{1} \mathrm{H}$ NMR using 1,1,2,2-tetrachloroethane as internal standard, Solvent: $5 \mathrm{~mL}$ toluene, $0.5 \mathrm{~mL}$ water, $4 \mathrm{~h}, 1.77 \mathrm{mmol} \mathrm{L}$-Lactic acid, reaction temperature $140^{\circ} \mathrm{C}$.

${ }^{\text {b }} \mathrm{MOF}+$ co-catalyst $\left(0.1 \mathrm{mmol} \mathrm{Cs}_{2} \mathrm{CO}_{3}\right)$.

In order to increase the reaction yield, a base was added as cocatalyst using the same reaction conditions. These results are summarized in Table 2, illustrating that the addition of base as co-catalyst improves the yield towards lactide. $\mathrm{Cs}_{2} \mathrm{CO}_{3}$ was added as co-catalyst using optimum reaction conditions; temperature $140{ }^{\circ} \mathrm{C}$, catalyst loading $60 \mathrm{mg}$ of different MOFs, $0.5 \mathrm{~mL}$ water, $\mathrm{Cs}_{2} \mathrm{CO}_{3}(0.1 \mathrm{mmol})$ and toluene as solvent (Fig. S5). Subsequently, a blank reaction containing only base $\left(\mathrm{Cs}_{2} \mathrm{CO}_{3}\right)$ and lactic acid was performed (Table 3). Surprisingly, $\mathrm{Cs}_{2} \mathrm{CO}_{3}$ alone can act as a very active catalyst towards the synthesis of lactide giving a high yield. This is the first example demonstrating the direct synthesis of lactide from lactic acid with avoiding racemization in presence of only simple bases as catalysts. In particular, bases such as $\mathrm{Cs}_{2} \mathrm{CO}_{3}$ demonstrated a very particular activity towards the synthesis of lactide from LA.

Considering the efficient effect of the base various reaction conditions were investigated using $\mathrm{Cs}_{2} \mathrm{CO}_{3}$. (Table 3 ) We started the reaction under the reaction conditions that were investigated using only MOF as catalyst $\left(140^{\circ} \mathrm{C}, 4 \mathrm{~h}, 0.5 \mathrm{~mL}\right.$ water, toluene and $0.1 \mathrm{mmol}$ base). It was revealed that the optimum reaction time is $3 \mathrm{~h}$ (Table 3 . entry 2) and the ideal catalyst amount is $0.1 \mathrm{mmol}$. Thereafter, different bases, such as $\mathrm{K}_{2} \mathrm{CO}_{3}, \mathrm{KOH}$, and 2-methylimidazole were applied under these reaction conditions (entries 9-11). Both NMR and chiral gas chromatography (GC) analyses were applied in order to determine the yield and selectivity towards the stereo-purity of lactide respectively.

Another important issue in the synthesis of lactide from lactic acid is the racemization. To determine various enantiomers, chiral gas chromatography was used. (Table S5). The results confirmed that applying a base as a catalyst can provide two important goals in the synthesis of

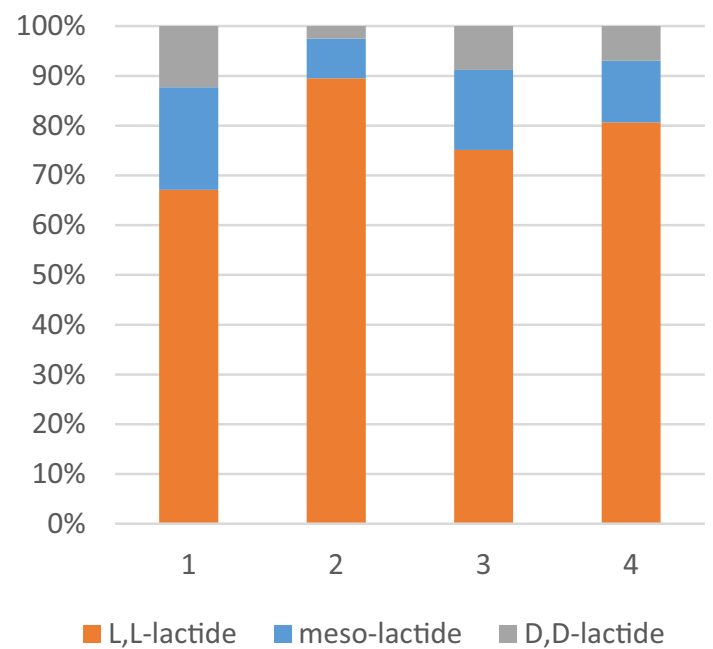

Fig. 1. Chiral-GC results of synthesized $\mathrm{L}, \mathrm{L}-\mathrm{Lactide}$ using different bases. 0.1: $\mathrm{K}_{2} \mathrm{CO}_{3} ; 2: \mathrm{Cs}_{2} \mathrm{CO}_{3} ; 3:$ 2-Methylimidazol; 4: $\mathrm{KOH}$.

lactide. Firstly, the yield of the reaction towards lactide is as high as $99 \%$ and secondly, the advantage of applying a base minimizes the amount of racemization.

Among various bases as a catalyst, $\mathrm{Cs}_{2} \mathrm{CO}_{3}$ demonstrated the highest yield towards lactide. It was shown by chiral GC analysis that $\mathrm{Cs}_{2} \mathrm{CO}_{3}$ could convert enantiopure L-LA up to $90 \%$ to L,L-Lactide and $<8 \%$ D,L lactide was formed. Hence, $\mathrm{Cs}_{2} \mathrm{CO}_{3}$ is an efficient catalyst, which can convert fully the LA to lactide and with a minimum amount of racemization.

Moreover, having 5 to $15 \mathrm{~mol} \%$ D,L-Lactide in the synthesis of lactide from enantiopure L-LA is common in the industrial lactide production [24, 25]. The yield and chiral-GC results are summarized in (Table 3 ) and (Fig. 1).

This developed procedure is a robust and convenient synthetic method of enantiopure L,L-lactide in terms of economics, energy and time. For the workup of the reaction, HPLC was used for the separation of product mixture. (Table S6).

\section{Mechanism}

As discussed in the introduction the synthesis of lactide from an aqueous solution of lactic acid includes two steps. First, a pre-polymer is made via removal of water from the lactic acid aqueous solution and second is an intermolecular esterification process yielding the desired lactide. Using the above results, a mechanism is proposed for the synthesis of L,L-lactide from LA using $\mathrm{Cs}_{2} \mathrm{CO}_{3}$ as a catalyst. (Fig. 2) The initial step is the pre-polymer generation from the lactic acid aqueous

Table 3

Different bases used as catalyst for the Lactide formation.

\begin{tabular}{|c|c|c|c|c|c|}
\hline Entry & Base (mmol) & Temperature $\left({ }^{\circ} \mathrm{C}\right)$ & Time (h) & Conversion (\%) & $\%$-yield ${ }^{\text {a }}$ \\
\hline 1 & $\mathrm{Cs}_{2} \mathrm{CO}_{3}(0.1)$ & 140 & 4 & 100 & 99 \\
\hline 2 & $\mathrm{Cs}_{2} \mathrm{CO}_{3}(0.1)$ & 140 & 3 & 100 & 99 \\
\hline 3 & $\mathrm{Cs}_{2} \mathrm{CO}_{3}(0.1)$ & 140 & 2 & 94 & 91 \\
\hline 4 & $\mathrm{Cs}_{2} \mathrm{CO}_{3}(0.14)$ & 140 & 3 & 100 & 99 \\
\hline 5 & $\mathrm{Cs}_{2} \mathrm{CO}_{3}(0.08)$ & 140 & 3 & 98 & 94 \\
\hline 6 & $\mathrm{Cs}_{2} \mathrm{CO}_{3}(0.1)$ & 120 & 3 & 91 & 88 \\
\hline 7 & $\mathrm{Cs}_{2} \mathrm{CO}_{3}(0.1)$ & 130 & 3 & 95 & 93 \\
\hline 8 & $\mathrm{Cs}_{2} \mathrm{CO}_{3}(0.1)$ & 135 & 3 & 98 & 95 \\
\hline 9 & $\mathrm{~K}_{2} \mathrm{CO}_{3}(0.1)$ & 140 & 3 & 93 & 90 \\
\hline 10 & $\mathrm{KOH}(0.1)$ & 140 & 3 & 99 & $>97$ \\
\hline 11 & 2-Methylimidazole (0.1) & 140 & 3 & 98 & $>95$ \\
\hline
\end{tabular}

Solvent: $5 \mathrm{~mL}$ toluene, $0.5 \mathrm{~mL}$ water, $1.77 \mathrm{mmol}$ L-lactic acid.

${ }^{\text {a }}$ Yield was determined by ${ }^{1} \mathrm{H}$ NMR using 1,1,2,2-tetrachloroethane as the internal standard. 


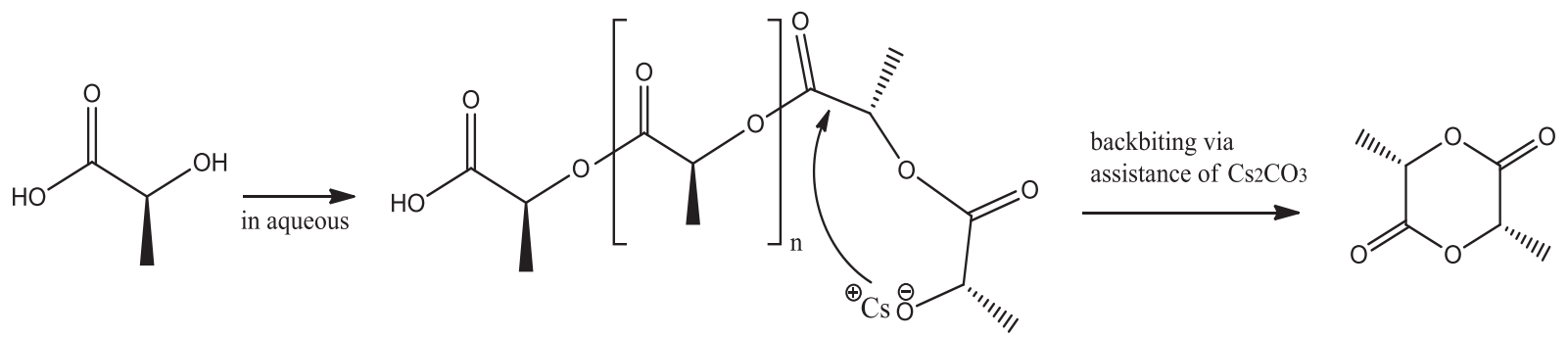

Fig. 2. Proposed mechanism for the synthesis of L,L-lactide.

solution [13]. Afterward, the next step involves an endothermic transesterification which is facilitated by $\mathrm{Cs}_{2} \mathrm{CO}_{3}$ through a backbiting mechanism. $\mathrm{Cs}_{2} \mathrm{CO}_{3}$ is known to be specifically efficient in esterification reactions [26].

In order to comprehend the second step of the mechanism, a reaction was performed using $\mathrm{Cs} 2 \mathrm{CO} 3$ as a catalyst in a closed system in absence of water and without extraction under identical reaction conditions $\left(140{ }^{\circ} \mathrm{C}, 3 \mathrm{~h}\right)$. The NMR results illustrated that still $>50 \%$ lactide was formed demonstrating the inherent affinity of cesium carbonate for the cyclization. Consequently, one can conclude that by using the liquid-liquid extraction system a higher yield of the cyclic dimer product L,L-lactide and lower amount of side products is obtained since the equilibrium is directed to the right due to the constant water removal.

\section{Conclusions}

In conclusion, various MOFs and bases were applied as catalysts for the direct synthesis of L,L-lactide from LA. The results presented that although MOFs are active catalysts for this reaction, their low stability in presence of water and LA decreases their efficiency. In contrast, we found a unique catalytic ability of cesium carbonate for the synthesis of lactide. Moreover, $\mathrm{Cs}_{2} \mathrm{CO}_{3}$ showed a high activity and selectivity (measured by chiral-GC) for the stereo-pure L,L-lactide synthesis with an almost complete conversion of LA. This is a direct one-step process which is efficient in energy, time and costs. To the best of our knowledge, this is the first report of using a regular base as an active catalyst for the synthesis of lactide from LA with high stereo-purity.

\section{Acknowledgment}

M. G expresses her deep appreciation to the Chinese Scholarship Council (CSC) for the financial support (grant 20150XZ063). F.V. acknowledges the support from the Russian Foundation for Basic Research ( $\mathrm{N}^{\circ}$ 18-29-04047) and Tomsk Polytechnic University Competitiveness Enhancement Program grant (VIU-195/2018).

\section{Appendix A. Supplementary data}

Supplementary data to this article can be found online at https:// doi.org/10.1016/j.catcom.2018.06.003.

\section{References}

[1] R.U. Halden, Plastics and health risks, Annu. Rev. Public Health 31 (2010) 179-194.

[2] R.C. Thompson, C.J. Moore, F.S. Vom Saal, S.H. Swan, Phil. Trans. R. Soc. B 364 (1526) (2009) 2153-2166.

[3] R.A. Gross, B. Kalra, Science 297 (2002) 803-807.

[4] D. Garlotta, J. Polym. Environ. 9 (2001) 63-84.

[5] P. Gruber, D.E. Henton, J. Starr, Polylactic acid from renewable resources, in: B. Kamm, P.R. Gruber, M. Kamm (Eds.), Biorefineries - Industrial Processes and Products, Status Quo and Future Directions, 2 Wiley-VCH, 2006, pp. 381-407.

[6] S. Inkinen, M. Hakkarainen, A. Albertsson, A. Södergård, Biomacromolecules 12 (2011) 523-532.

[7] J.R. Rocca-Smith, O. Whyte, C. Brachais, D. Champion, F. Piasente, E. Marcuzzo, A. Sensidoni, F. Debeaufort, T. Karbowiak, ACS Sustain. Chem. Eng. 5 (2017) 2751-2762.

[8] R.A. Gross, B. Kalra, Science 297 (2002) 803-807.

[9] L. Shen, E. Worrell, M. Patel, Biofuel Bioprod. Biorg. 4 (2010) 25-40.

[10] M. Jamshidian, E.A. Tehrany, M. Imran, M. Jacquot, St. Desobry, Compr. Rev. Food Sci. Food Saf. 9 (2010) 552-571.

[11] M. Dusselier, P.V. Wouwe, A. Dewaele, E. Makshina, Bert F. Sels, Energy Environ. Sci. 6 (2013) 1415-1442.

[12] K. Masutani, Y. Kimura, A. Jimenez, M. Peltzer, R. Ruseckaite (Eds.), Poly(lactic acid) Science and Technology: Processing, Properties, Additives and Applications, Royal Society of Chemistry, 2015, pp. 1-36.

[13] M. Dusselier, P.V. Wouwe, A. Dewaele, P.A. Jacobs, B.F. Sels, Science 349 (6243) (2015).

[14] M. Noda, H. Okuyama, Chem. Pharm. Bull. 47 (1999) 467-471.

[15] T. Motoyama, T. Tsukegi, Y. Shirai, H. Nishida, T. Endo, Polym. Degrad. Stab. 92 (2007) 1350-1358.

[16] R. Hagen, A. B. Verweij, U. Muehlbauer, H. R. Kricheldorf, J. Schulze, W. Tietz, K.D. Goehler, WO Pat., 2010022966A2, (2010).

[17] D.K. Yoo, D. Kim, D.S. Lee, Macromol. Res. 14 (2006) 510-516.

[18] a) Y.M. Zhang, P. Wang, N. Han, H.F. Lei, Macromol. Rapid Commun. 28 (2007) 417-421;

b) X.G. Yang, L.J. Liu, Polym. Bull. 61 (2008) 177-188.

[19] D.T. Vu, A.K. Kolah, N.S. Asthana, L. Peereboom, C.T. Lira, D.J. Miller, Fluid Phase Equilib. 236 (2005) 125-135.

[20] B. Mousavi, S. Chaemchuen, S. Phatanasri, C. Chen, C. Zeng, R. Ganguly, F. Verpoort, Arab. J. Chem. (2017), http://dx.doi.org/10.1016/j.arabjc.2017.09. 011.

[21] H. Furukawa, F. Gandara, Y. Zhang, J. Jiang, L. Queen, M.R. Hudson, M. Yaghi, J. Am. Chem. Soc. (11) (2014) 4369-4381.

[22] K. Zhou, B. Mousavi, Z. Luo, S. Phatanasri, S. Chaemchuen, F. Verpoort, J. Mater. Chem. A 5 (2017) 952.

[24] P. R. Gruber et al. U.S. patent 5247058 (1993).

[25] W. G. O'Brien, L. A. Cariello, T. F. Wells, WO patent 9606092A1 (1996).

[26] J.C. Lee, Y. Seok Oh, S.H. Cho, J.D. Lee, Org. Prep. Proceed. Int. 28 (1996) 480-483. 